\title{
TO STUDY THE CORRELATION BETWEEN SPIROMETRY AND CAT SCORE IN PATIENTS OF COPD
}

\author{
Abhishek Srivastava1, Shikhar Tripathi², Mridula Srivastava ${ }^{3}$, Vinod Kumar ${ }^{4}$
}

${ }^{1}$ Associate Professor, Department of Pulmonary Medicine, Mayo Institute of Medical Sciences, Barabanki, Uttar Pradesh.

${ }^{2}$ Assistant Professor, Department of Pulmonary Medicine, TSM Medical College.

${ }^{3}$ Assistant Professor, Department of Paediatrics, Mayo Institute of Medical Sciences, Barabanki, Uttar Pradesh.

${ }^{4}$ Senior Resident, Department of Pulmonary Medicine, Mayo Institute of Medical Sciences, Barabanki, Uttar Pradesh.

\section{ABSTRACT}

\section{BACKGROUND}

The objective of this study is to study the correlation between spirometry and CAT score in patients of COPD.

\section{MATERIALS AND METHODS}

All the patients attending the OPD within the study period with history of breathlessness on exertion were evaluated. The diagnosis of COPD was made after spirometry and patients were accordingly classified on the basis of GOLD Guideline. CAT (COPD assessment test) questionnaire were being filled up by these patients who made the study group and classified into four groups according to their scores. The correlation between the two were analysed using various statistical tests.

\section{RESULTS}

Out of all the patients, total 90 patients of COPD were enrolled in the study. Among these, the mean age of the patients were $61.52 \pm$ 6.4 (48 - 72), 77 (85.5\%) were males and 13 (14.4\%) were females; 85.5\% had smoking history and $14.4 \%$ had history of biomass exposure. Majority of the patients (63.7\%) were falling in Group 2 of CAT score indicating medium airflow obstruction. Patients with severe COPD (Stage III and IV) had similarly higher CAT scores showing a direct correlation, which was significant ( $p<0.001$ ). Patients in whom post bronchodilator FEV1\% was significantly decreased had significantly increased CAT scores (p < 0.001), showing an inverse correlation between the two.

\section{CONCLUSION}

Incorporation of CAT score can help in early detection and proper management of COPD patients, especially in resource poor setting, where spirometry is not feasible.

\section{KEYWORDS}

COPD, Spirometry, CAT Score Correlation.

HOW TO CITE THIS ARTICLE: Srivastava A, Tripathi S, Srivastava M, et al. To study the correlation between spirometry and CAT score in patients of COPD. J. Evolution Med. Dent. Sci. 2017;6(20):1636-1638, DOI: 10.14260/Jemds/2017/358

\section{BACKGROUND}

Chronic Obstructive Pulmonary Disease (COPD) is a major health problem worldwide, and is responsible for significant morbidity in affected adults. COPD is characterised by not fully reversible chronic airflow limitation, a range of pathological changes in the lung and some significant extrapulmonary effects with important comorbidities, all of which may contribute to the severity of the disease. ${ }^{1}$ COPD is currently the fourth leading cause of death in the world and is projected to be the third most common cause of death by $2020.2,3$ COPD should be suspected in any patient aged 40 years or more with symptoms of cough, sputum production or breathlessness and/or a history of exposure to risk factors, in particular smoking. 4,5

According to the GOLD guideline, Spirometry is needed for both diagnosis and staging of COPD. Spirometry can

Financial or Other, Competing Interest: None.

Submission 02-02-2017, Peer Review 24-02-2017,

Acceptance 03-03-2017, Published 09-03-2017.

Corresponding Author:

Dr. Abhishek Srivastava,

Associate Professor,

Department of Pulmonary Medicine,

Mayo Institute of Medical Sciences,

Gadia Barabanki, Uttar Pradesh.

E-mail: drabhishek.17@gmail.com

DOI: $10.14260 /$ jemds $/ 2017 / 358$ confirm the presence of airway obstruction, can provide an index of disease severity and also enable the monitoring of disease progression. ${ }^{1}$ The health status of patients with COPD is currently being assessed using COPD Assessment Test (CAT), which is a quick and easy test for patients to complete and provides a score that indicates the impact of the disease on their health status. There is increasing evidence that the CAT is a promising tool to quantify COPD exacerbations. Accordingly, the CAT score can be a useful marker in clinical trials that evaluate the effectiveness of treatments in prevention or management of COPD exacerbations or that investigate the disease progression over time. ${ }^{6}$ In the future, the CAT score could also be used as an outcome measure in clinical practice to track changes in patient's overall health status and to improve communication between patients and healthcare professionals.

As there are very few Indian studies showing the correlation between spirometry and CAT score, in the present study we tried to evaluate the above correlation in COPD patients.

\section{MATERIALS AND METHODS}

This prospective observational study was carried out in the patients attending the OPD of Department of Pulmonary Medicine, Mayo Institute of Medical Sciences, Barabanki, UP. A total of 90 patients were enrolled in the present study over a period of one year beginning from May 2014 to April 2015. 


\section{Inclusion Criteria}

1. COPD patients diagnosed as per GOLD Guidelines in stage I, II, III and IV.

2. Patients who have no COPD exacerbations over the preceding 6 weeks and willingness to undergo study related testing that included spirometry and had documented airflow limitation (as evidenced by post bronchodilator FEV1/FVC ratio $<70 \%$ ) at initial evaluation.

3. Patient should be in a stable state for one month.

4. Patient should have no comorbidities.

\section{Exclusion Criteria}

1. Patients showing full reversibility after bronchodilator therapy on spirometry.

2. COPD with any parenchymal lung disease.

3. Patient on long-term oxygen therapy.

All the patients with dyspnoea attending the OPD of Pulmonary Medicine during the study period were examined and evaluated on the grounds of COPD. Apart from clinical and radiological evidences suggesting the probability of COPD, patients underwent spirometric evaluation for final confirmation of the disease. PFT was performed at least 12 hours after the withdrawal of inhaled bronchodilators. Patients were then classified according to disease severity as Stage I, II, III, IV as per the GOLD Guideline.

CAT Questionnaire were distributed among the study group and were duly filled after proper explanation to the patients. CAT has a scoring range from 0 to 40 , and is classified into four groups accordingly.

- Group 1-< 10

- Group 2-10 - 20

- Group 3-21 - 30

- Group 4-> 30

Data was analysed using SPSS 20 (SPSS Inc., Chicago, IL) Software package. Results were expressed as mean \pm standard deviation, unless otherwise stated. In order to evaluate the correlation between parametric variables, the Pearson's correlation coefficient was utilised. P values $<0.05$ were considered statistically significant.

\section{RESULTS}

During the study period of one year, a total of 90 patients who fulfilled the inclusion criteria were enrolled for the study.

Table 1 shows distribution of patients on the basis of age (years), sex (M/F), occupation, smoking history, biomass exposure in women.

\begin{tabular}{|c|c|c|}
\hline \multicolumn{2}{|c|}{ Demographic Data } & $\mathrm{N}=90$ \\
\hline \multicolumn{2}{|c|}{ Age (Year)* } & $61.52 \pm 6.4(48-72)$ \\
\hline \multicolumn{2}{|c|}{$\operatorname{Sex}(M: F)$} & $(77: 13)$ \\
\hline \multirow{5}{*}{ Occupation $\#$} & Servicemen & $12(13.3 \%)$ \\
\hline & Farmer & $41(45.6 \%)$ \\
\hline & Housewives & $10(11.1 \%)$ \\
\hline & Labourers & $15(16.7 \%)$ \\
\hline & Others & $12(13.3 \%)$ \\
\hline \multicolumn{2}{|c|}{ Smoking history\# } & $77(85.5 \%)$ \\
\hline \multicolumn{2}{|c|}{ Biomass exposure } & $13(14.4 \%)$ \\
\hline
\end{tabular}

$*=$ value express as mean \pm standard deviation (Min Max), \#= value express as $\mathrm{N}(\%), \mathrm{M}=$ Male, $\mathrm{F}=$ Female.

Table 2 shows the number of patients and impact of COPD on health status as assessed by CAT score.

\begin{tabular}{|c|c|}
\hline CAT Score (Impact Level) ${ }^{\mathbf{1 0 5}}$ & Patients \\
\hline Group 1 & $1(1.1 \%)$ \\
\hline Group 2 & $57(63.7 \%)$ \\
\hline Group 3 & $26(28.9 \%)$ \\
\hline Group 4 & $6(6.7 \%)$ \\
\hline Total & $\mathbf{9 0}(\mathbf{1 0 0 . 0} \%)$ \\
\hline $\begin{array}{c}\text { Table 2. Showing Number of Patients and Impact of COPD } \\
\text { on Health Status }\end{array}$ \\
\hline
\end{tabular}

Group 1 = CAT score < 10 (Low); Group 2 = CAT score 10 20 (Medium); Group 3 = CAT score 21 - 30 (High); Group $4=$ CAT score $>30$ (Very high).

Table 3- This table shows the correlation between CAT score and COPD severity according to GOLD classification. On comparison of the patients among the four COPD GOLD stages, we observe that while there was no significant difference in the age the $\mathrm{p}$ value was highly significant in CAT Score $(\mathrm{p}<0.001)$.

\begin{tabular}{|c|c|c|c|c|c|}
\hline \multicolumn{7}{|c|}{ COPD Gold Stage } \\
\hline & $\begin{array}{c}\text { Stage I } \\
\text { (Mild) }\end{array}$ & $\begin{array}{c}\text { Stage II } \\
\text { (Moderate) }\end{array}$ & $\begin{array}{l}\text { Stage III } \\
\text { (Severe) }\end{array}$ & $\begin{array}{c}\text { Stage IV } \\
\text { (Very } \\
\text { Severe) }\end{array}$ & $\begin{array}{c}\text { P- } \\
\text { value }\end{array}$ \\
\hline N & $\mathbf{2 6}$ & $\mathbf{3 4}$ & $\mathbf{2 6}$ & $\mathbf{4}$ & \\
\hline $\begin{array}{c}\text { Age } \\
\text { (Year) }\end{array}$ & $62.31 \pm 6.6$ & $60.44 \pm 6.1$ & $62.92 \pm 5.7$ & $56.50 \pm 10.1$ & 0.167 \\
\hline $\begin{array}{c}\text { CAT } \\
\text { Score }\end{array}$ & $17.35 \pm 3.1$ & $20.56 \pm 4.9$ & $24.19 \pm 4.2$ & $30.00 \pm 3.2$ & $<$ \\
\hline \multicolumn{7}{|c|}{ Table 3. Characteristics of the Studied Population at } \\
Baseline (n= 90)
\end{tabular}

$\mathrm{P}<0.001=$ Highly Significant

Table no. 4 shows distribution of post bronchodilator FEV1\% in respect to CAT categories, which shows that there is an inverse relation of CAT score with disease severity in terms of post bronchodilator FEV1\% with a highly significant $p$ value.

\begin{tabular}{|c|c|c|c|c|c|}
\hline \multicolumn{2}{|c|}{ CAT Categories } & $\mathbf{N}$ & $\begin{array}{c}\text { Mean } \pm \\
\text { Standard }\end{array}$ & Range & $\begin{array}{c}P \\
\text { value }\end{array}$ \\
\hline \multirow{5}{*}{$\begin{array}{l}\text { Post- } \\
\text { bronchodilator } \\
\text { FEV1\% }\end{array}$} & Group 1 & 1 & $82.00 \pm 0.0$ & $(82-82)$ & \multirow{5}{*}{$\begin{array}{c}< \\
0.001\end{array}$} \\
\hline & Group 2 & 57 & $69.58 \pm 14.8$ & $(34-86)$ & \\
\hline & Group 3 & 26 & $43.58 \pm 12.5$ & $(20-69)$ & \\
\hline & Group 4 & 6 & $42.17 \pm 18.8$ & $(26-66)$ & \\
\hline & Total & 90 & $60.38 \pm 19.1$ & $(20-86)$ & \\
\hline \multicolumn{6}{|c|}{ Table 4} \\
\hline
\end{tabular}

Group 1= CAT score < 10 (Low); Group 2= CAT score 10 20 (Medium); Group 3= CAT score 21 - 30 (High); Group 4= CAT score $>30$ (Very high), N= Sample size, $\mathrm{SD}=$ Standard deviation, $<0.001=$ Highly Significant.

\section{DISCUSSION}

COPD is a progressive condition leading to morbidity and mortality and is characterised by cough, dyspnoea and sputum production. COPD is a condition with persistent airflow limitation and systemic inflammation affecting the lungs and other organs and impairing Quality of Life by several mechanisms.7 Spirometric evaluation of FEV1 can 
classify the disease, but it does not reflect the multidimensional effect of the disease on health status.

The COPD Assessment Test Score (CAT score), which is an eight item, self-administered questionnaire is a new scoring system for COPD patients which provides a simple method for assessing the impact of disease on the patient's health. ${ }^{8}$

In the present study, the correlation between Spirometry and CAT score in patients of COPD was carried out. In our study, we found mean age of patients was $61.52 \pm 6.4 \mathrm{yrs}$. and male patients $77(85.6 \%)$ were more ailment to COPD out of 90 patients that is comparable to other study of Hassan Ghobadi et $\mathrm{al}^{9}$ and Sarioglu N et $\mathrm{al}^{10}$ as $59.60 \pm 11.93$ years and $63.6 \pm 10.5$ years respectively. In our study, out of 90 patients 13 patients (14\%) were having COPD with attributable risk as biomass exposure. So it affirms the belief that indoor and outdoor pollution plays an important role in the pathogenesis of COPD in nonsmokers. ${ }^{11}$

In our study, we found significant correlation between FEV1\% and total CAT score ( $\mathrm{r}=-0.579, \mathrm{p}<0.001)$. This is similar to some previous researches done by Hassan Ghobadi et al $^{9}$ as correlation $(\mathrm{r}=-0.55, \mathrm{p}<0.001)$, and Choudhary Sumer et al. ${ }^{12}$ Post-bronchodilator FEV1\% was significantly decreased and the CAT score was significantly increased ( $\mathrm{p}<$ 0.01 ) showing an inverse correlation between the two. These results suggest that health impairment due to COPD is associated with low FEV1 and a high CAT score. This is also similar to a study done by Alex J Mackay et al,13 which showed that patients with severe COPD showed significantly higher CAT score $(\mathrm{p}<0.032)$.

From the present study, it is also evident that CAT score and GOLD classification has a positive correlation with $\mathrm{p}<$ 0.001 , which is significant. These findings are similar in the studies done by Hassan Ghobadi et $\mathrm{al}^{9}$ and Choudhary Sumer et al. ${ }^{12}$

Further, post bronchodilator FEV1\% and FEV1/FVC were reduced in COPD patients and the correlation of smoking with airflow limitation is in concordance with previous researches. ${ }^{1}$

\section{CONCLUSION}

In developing country like India, there is a lack of disease awareness and paucity of adequate tools to diagnose the respiratory illnesses at its early stages. Spirometric evaluation of subjects gives the burden of the COPD, but as it is not available in most of the clinical settings we need to have a subjective tool which can predict the severity of airway obstruction.

The CAT questionnaire, which is a simple and reliable tool proves to be a sensitive test in detecting COPD health status. There is a significant correlation between FEV1\% and CAT scores, so it can be a better assay for evaluating the severity of disease, management of patient's response to treatment and prognosis.
Spirometry still is essential and the most objective measurement for the diagnosis of air limitation to determine the severity of COPD, but the incorporation of CAT scoring can help in early detection and proper management of COPD patients, especially in resource poor setting. Early detection also helps to improve the quality of life and productivity.

\section{REFERENCES}

[1] The Global Initiative for Chronic Obstructive Lung Disease (GOLD), Global strategy for the diagnosis, management, and prevention of COPD, updated 2015. http://www.goldcopd.org.

[2] World Health Report. Geneva: World Health Organization 2000. Available from URL: http://www.who.int/whr/2000/en/statistics.htm.

[3] Petty TL. Definition, epidemiology, course, and prognosis of COPD. Clin Cornerstone 2003;5(1):1-10.

[4] National Collaborating Centre for Chronic Conditions. Chronic obstructive pulmonary disease. National clinical guideline on management of chronic obstructive pulmonary disease in adults in primary and secondary care. Thorax 2004;59(Suppl 1):1-232.

[5] Celli BR, MacNee W. ATS/ERS task force. Standards for the diagnosis and treatment of patients with COPD: a summary of the ATS/ERS position paper. Eur Respir J 2004;23(6):932-46.

[6] Chetta A, Olivieri D. The COPD assessment test in the evaluation of chronic obstructive pulmonary disease exacerbations. Expert Rev Respir Med 2012;6(4):3735.

[7] Fabbri LM, Rabe KF. From COPD to chronic systemic inflammatory syndrome? Lancet 2007;370(9589):797- 9.

[8] Jones PW, Harding G, Berry P, et al. Development and first validation of the COPD assessment test. Eur Respir J 2009;34(3):648-54.

[9] Ghobadi H, Ahari SS, Kameli A, et al. The relationship between COPD assessment test (CAT) scores and severity of airflow obstruction in stable COPD patients. Tanaffos 2012;11(2):22-6.

[10] Sarioglu N, Alpaydin AO, Coskun AS, et al. Relationship between BODE index, quality of life and inflammatory cytokines in COPD patients. Multidiscip Respir Med 2010;5(2):84-91.

[11] Zeng G, Sun B, Zhong N. Non-smoking related chronic obstructive pulmonary disease: a neglected entity. Respirology 2012;17(6):908-12.

[12] Sumer C, Rini A, Tayade B, et al. CAT score in chronic obstructive pulmonary disease, impact on health: assessment in our region. Panacea Journal of Medical Sciences 2016;6(1):13-9.

[13] Mackay AJ, Donaldson GC, Patel AR, et al. Usefulness of the chronic obstructive pulmonary disease assessment test to evaluate severity of COPD exacerbations. Am J Respir Crit Med 2012;185(11):1218-24. 